\title{
Ethical Leadership Essential for an Ethical Environment
}

\author{
Dr Michelle Mey \\ Nelson Mandela Metropolitan University \\ Email:michelle.mey@nmmu.ac.za \\ Prof Hendrik Lloyd \\ Nelson Mandela Metropolitan University \\ Email: hendrik.lloyd@nmmu.ac.za \\ Koman Ramalingum \\ Nelson Mandela Metropolitan University \\ Email: komanr@polka.co.za
}

Doi:10.5901/mjss.2014.v5n20p897

\section{Abstract}

High profile scandals and ethical misconduct in companies around the world have brought about a renewed interest in business ethics, specifically the need for a better understanding of the roles and responsibilities of leadership in promoting ethical behaviour. Against this background, a quantitative analysis was conducted among companies operating in South Africa's Eastern Cape Province's automotive industry. The aim of the study was to determine the ethics-related roles played by the leadership at these organisations and the extent to which they contributed to establishing and maintaining an ethical organisational environment. A structured online questionnaire was used to collect the data. The results revealed that the organisations in the sample are highly ethical due to ethical and committed leadership and moreover the presence of ethics related interventions, including a code of ethics, adherence to internal and external governance requirements, compliance with legislation and encouragement and disclosure of unethical behaviour.

Keywords: business ethics; ethical leadership, automotive industry; South Africa; Eastern Cape Province

\section{Introduction}

"60\% of misconduct involved someone from supervisory level to top management with nearly $24 \%$ of misdeeds involving senior management".

This alarming statistic was revealed in the latest National Business Ethics Survey (NBES), conducted in 2013 in which 6420 employees from American companies participated. Of further concern was the fact that while the survey revealed that misconduct was down overall, a relatively high percentage of misconduct was being committed by managers - the very people who are supposed to set a good example of ethical conduct and make sure employees honour company rules. This clearly does not bode well for the prevalence of an ethical environment and highlights the need for the on-going focus on the ethical conduct of an organisation's leadership.

Since the Enron scandal in 2001, there has been a flurry of ethical misconduct in companies around the world, South Africa included, which have been blamed in part on the unscrupulous and unethical behaviour of senior management (Fombrun \& Foss, 2004; Schoeman, 2012; van Zyl \& Lazenby, 1999). Such corporate scandals and financial disasters have not only threatened the position of many senior managers but also the financial survival of the companies over which they preside (Knights \& O'Leary, 2005:359). Moreover, they have raised the profile of and brought renewed interest to business ethics - specifically the need for a better understanding of the roles and responsibilities of leadership in promoting ethical behaviour.

If an organisation's leaders and senior management are critical to setting the tone for ethics and values and for the upholding thereof, what then are their primary duties in this respect? A review of literature on international best practice indicates that an organisation's leadership is responsible for the preparation, with staff, of policies and codes to guide and direct ethical behaviour with regards to the organisation's stakeholders (employees, shareholders, suppliers, customers 
and the wider society). Additionally, the leadership of organisations is required to comply with external governance and legislative requirements. Another key role of leadership is to encourage the reporting of misconduct, through whistle blower protection, and to have rewards and penalties in place for recognising ethical behaviour and to curb misconduct.

Against this background, a quantitative analysis was conducted among companies operating in South Africa's Eastern Cape Province's automotive industry to determine the ethics-related roles played by the leadership at these organisations and the extent to which they contributed to establishing and maintaining an ethical organisational environment. A structured online questionnaire, based on a study conducted by Mey (2004) and revised according to the literature reviewed, was used to collect the data. This paper reports on the roles of leadership in ensuring an ethical environment as identified in the literature and based on the empirical findings from the study. It concludes with recommendations for improving an organisation's ethical environment through effective and ethical leadership. The review of literature follows.

\section{Literature Review}

This section looks at the importance of being ethical, the components and elements of an ethical organisation, external governance, legislative requirements and ethical leadership.

\subsection{The importance of being ethical}

"Business ethics is about identifying and implementing standards of conduct in and for business that will ensure that the interests of stakeholders are respected. It is about a conception of what is good (values and standards) that guides the business (self) in its interaction with others (stakeholders)" (Rossouw \& van Vuuren, 2010:5). As business ethics applies to employees, management and the organisation as a whole; it can be personal or institutional in nature (Gruble, 2011; Pattan, 1984). Furthermore, business ethics involves different levels, namely: the macro level, where concern is around the role of business in society and its moral and legal obligation to abide by the law, secondly the corporate level, which pertains to ethical issues facing individual corporate entities when formulating and implementing strategies, and, thirdly at the individual level, which involves the values, behaviour and actions of individuals within organisations (Fieser, n.d.; Josephson, 2012).

When implementing business ethics, companies can adopt either a stockholder/shareholder-focused or stakeholder-focused approach (Freeman, 2001; Freeman \& Reed, 1983) In the case of former, the attention is on the interests of the owners and the emphasis is on generating profit. In the stakeholder-focused approach, companies act and decide with the interests of all stakeholders, including employees, customers, suppliers and the broader community, in mind. The ethical expectations that society has of modern corporations has shifted and changed in recent times and corporations are increasingly being regarded as integral and key players in the wellbeing of society (Rossouw \& van Vuuren, 2013: 99). This is especially relevant in the South African context where new corporate codes of conduct legislation such as the King Report on Corporate Governance 2009 place an even greater burden on an organisation's board of directors and senior management to take all stakeholders into account when making ethical decisions (Barnard, 2012: 10). Furthermore, there is growing recognition, supported by research, that good ethics can have a positive economic impact on the performance of firms and that 'good ethics is good business' (Joyner \& Payne, 2002: 297). Companies that commit to ethical behaviour toward their stakeholders or emphasise compliance with their code of conduct perform better financially than those that do not (Chauhan \& Chauhan 2002 in Barnard, 2012; Verschoor, 1998). 'Many organisations acknowledge that the preservation of corporate reputation, respect for ethically discerning consumers and the protection of company assets against fraud and corruption, result in investor confidence and good business' (van Vuuren, 2002: 21). If being ethical is good for business, what then are the components and elements of an ethical organisation?

\subsection{An ethical organisational environment}

\subsubsection{Components and elements of an ethical organisation}

According to van Vuuren (2002:22), 'an ethical organisation is one that has a strong ethical value orientation, lives those values, and practices them when engaging with all internal and external stakeholders'. Van Vuuren (2002) further proposes a three levelled strategy for ethics to become truly engrained into an organisation's culture, namely the formulation of an ethics management system at a strategic level, the design of systems for strategy implementation and 
finally the application of ethical principles in the daily activities of every employee. In addition, Mayer (2011) proposes three key components of the ethical environment that work together to promote ethical behaviour: ethical leadership, ethical practices and an ethical climate. Ethical leaders set the tone for how employees behave in organisations by conducting themselves in a moral manner, and by taking decisions that are fair and in the best interest of their employees and other stakeholders, a view shared by Granger (2011), and Robbins and Judge (2009). Leaders are also expected to discipline employees who violate ethical standards. Ethical practices are actions or activities related to ethics that are repeated and recognisable in organisations; they are what organisations actually do. An ethical climate is created when there exists a general perception among employees that the organisation is ethical. Creating an organisational context that promotes ethical conduct is reliant on having policies and procedures in place with regards to acceptable behaviour and standards. In addition, Robbins and Judge (2009) include the importance of communicating ethical expectations, over and above having the necessary policies and codes. Furthermore, a key finding of the 2005 National Business Ethics Survey, conducted by the Ethics Resource Centre, was that an ethics communication strategy was not enough to create desired outcomes and that employees needed to see their superiors and peers demonstrate ethical behaviour in the work they do and the decisions they take (Seligson \& Choi, 2006: 2). Of importance, also, is for organisations to make ethics a conscious management focus, and to monitor and manage it. Measurement of ethics through regular ethics audits will assist an organisation to identify and timeously address ethical 'hot spots'.

Creating an ethical organisation starts with top management's commitment to ethics. (Lloyd \& Mey, 2010; van Vuuren, 2002). 'Starting with the CEO, senior managers must continually demonstrate the company's core values and reinforce standards of behaviour' (Archer, 2008: 32). Top management commitment should ideally be followed by the appointment of an ethics manager or officer to create and maintain an ethical organisational culture and to effectively manage corporate ethics. (van Vuuren, 2002). One of the main responsibilities of an ethics manager is to ensure that the organisation has a strong code of ethics that applies to all employees, has been prepared by both managers and employees (Archer, 2008) and includes issues that relate to all the organisation's stakeholders. It is crucial that management are positive role models as regards the code of ethics (Kaptein, 2010). The ethics manager would be responsible, also, for co-ordinating the orientation and training on ethical standards as well as for driving the communication efforts of the organisation with respect to reinforcing the company's standards of behaviour. In addition, the Ethics Resource Centre (ERC) has adopted the following key elements, based on the Federal Sentencing Guidelines for Organisations, as being necessary for an ethical environment to prevail (ERC, 2012): a specific office, telephone line, email address or website for advice about workplace ethics issues; a means for an employee to report confidentially or anonymously violations of ethics standards; evaluation of ethical conduct as part of regular performance appraisals and discipline for employees who violate ethics standards, a view supported by Archer (2008: 36) who purports that 'establishing standards of behaviour without being prepared to discipline will not promote compliance'. Furthermore, Lloyd and Mey (2010) argue that an ethics focused reward system is critical to institutionalising ethical behaviour.

Corporate ethics and standards of conduct are matters of internal governance; however, having an ethical organisational is determined also by the external governance requirements and the legislative context, which is discussed below.

\subsubsection{External governance and legislative requirements}

Corporate governance refers to the framework of rules and practices by which a board of directors ensures accountability, fairness and transparency in an organisation's relationship with all its stakeholders (BusinessDictionary.com, n.d.). In South Africa, the corporate governance landscape has been transformed and shaped largely by the King I, II and III Reports which require companies to take into account the organisation's impact on the larger community, to be socially and environmentally responsible as well as calling for ethical leadership and reporting on ethical performance (Institute of Directors Southern Africa, 2009).

\subsubsection{Social and Ethics Committee}

Against the backdrop of the King reports, Section 72 (4) of the Companies Act No. 71 of 2008 makes provision for a Social and Ethics Committee. Every state-owned company, listed public company and any other company that scored 500 public interest points in any two of the previous five years (based on the number of employees, annual turnover and third party liability) must have established a Social and Ethics Committee by 1 May 2012. The committee is appointed by the board and is required to report to the board on areas of "social and economic development", "good corporate citizenship", "impact of companies activities and products or services on communities", "consumer 
relationships" and "labour and employment" (Companies Act 71 of 2008). Managing ethics and reporting on ethics are now legal requirements in terms of the new Companies Act.

\subsubsection{Protected Disclosures Act No. 26 of 2000}

The Protected Disclosures Act No. 26 of 2000 is an initiative by the South African government to create an environment that facilitates the disclosure of information and to protect whistleblowers from harassment and victimisation (Protected Disclosures Act 26 of 2000). Whistleblowing refers to the disclosure of illegal, unethical or harmful practices in the workplace to parties, inside or outside the organisation, who might take action (Bainbridge, 2013; Miethe \& Rothschild, 1994). The disclosure of information is regarded as being in the public interest. Due to the potential risks for individual whistleblowers, it is imperative that organisations create an environment that protects and incentivises disclosures of unethical or illegal behaviour.

\subsection{Ethical leadership}

'Today's leaders must resist the powerful temptation of self-interest and must be motivated by broader values and principles based on a morally established duty owed and a fiduciary obligation' (Carlopia, 2002 in Caldwell, Hayes \& Long, 2010: 497).

The recent corporate scandals which demonstrated the lack of ethical conduct by Chief Executive Officers (CEOs) and other top leaders was an urgent call for exactly this type of leadership. 'The unethical actions of leaders caused the demise of some of the world's largest and most successful companies and in so doing demonstrated the enormous impact of leaders on their organisations through both their direct actions and by creating a climate that sanctioned ethically questionable practices' (Grojean, Resick, Dickson \& Smith, 2004: 224). As such, leaders' actions both directly and indirectly establish the ethical tone of an organisation by the actions that are encouraged, rewarded and demonstrated. Minkes, Small and Chatterjee (1999:332) went so far as to say that a 'CEO ought to state clearly that ethical behaviour is the cornerstone of his organisation and support this position through words and action'. An organisation's leaders also have the primary role in communicating and demonstrating the importance of ethical values to the organisation's members. In addition to setting the example and establishing clear expectations of ethical conduct, leaders impact the ethical climate through providing feedback, coaching and support regarding ethical behaviour and recognising and rewarding appropriate behaviour (Grojean et al, 2004). It is therefore clear that strong ethical leadership is necessary for an ethical environment to prevail. Who then constitutes the leadership of an organisation?

According to Rossouw and van Vuuren (2013:225), leadership can be exercised at various organisational levels and by various role players in organisations. While there is no universally agreed definition of what constitutes 'leadership', for the purposes of this paper, leadership refers, as proposed by Minkes, Small and Chatterjee (1999), to the board of directors, and senior management responsible for the direction of the organisation as well those employed at functional, departmental or divisional levels. In regard to leadership, ethics has to do with what leaders do and who leaders are. It is concerned with the nature of leader's behaviour and with their moral orientation (Khar, Praveen \& Aggarwal, 2011). According to Brown and Trevino (2006, in Barnard, 2012), higher level or senior managers should focus more on the external ethical environment while lower level managers should focus on the ethical environment of the organisation.

If, as advocated by Jondle, Ardichvilli and Mitchell (2014:31) that 'effective leaders lead effective organisations and ethical leaders lead ethical organizations, what then is ethical leadership? Ethical leadership has been defined by Brown, Trevino, and Harrison (2005: 120) as 'the demonstration of normatively appropriate conduct through personal actions and interpersonal relationships, and the promotion of such conduct to followers through two-way communication, reinforcement, and decision-making'. Ethical leaders are good role-models- they are honest and principled leaders who seek to do the right thing and who conduct their personal lives in an ethical manner. They tend to make fair and balanced decisions and they set, communicate, and enforce clear ethical standards among those they lead, and are supportive and caring leaders that listen to, and are trusted by, their subordinates (Brown \& Trevino, 2006 in Hansen 2011:41). For a person to be an ethical leader he or she must be both a 'moral person' and a 'moral manager' where a 'moral person' has a good character and is honest, trustworthy, caring and supportive while a 'moral manager' is one who leads others on the ethical dimension, allowing employees to know what is expected and to hold them accountable (Trevino \& Brown, 2004 in Bello, 2012: 230).

The literature reviewed clearly articulates that an ethical environment needs the required infrastructure including a code of ethics, an ethics officer and an ethics 'hot line' but this alone is not enough - even more importantly, it needs 
individuals who can differentiate between right and wrong, people who can make difficult decisions and are assertive enough to stand by the decisions they make (Singh, 2011). In other words an 'effective ethical organization needs effective leaders that 'walk the talk' exemplifying alignment of personal with organizational values' (Jondle, Ardichvilli \& Mitchell (2014:31). An overview of the research design employed in this study follows and includes discussion of the following: hypotheses, research methods, sampling, the research instrument, data collection, analysis procedures, and the validity and reliability of the research.

\section{Research Design}

\subsection{Research question}

To determine the ethics-related roles played by the leadership in the Eastern Cape automotive industry cluster and the extent to which they contributed to establishing and maintaining an ethical organisational environment

\subsection{Hypotheses}

The following hypotheses were constructed and tested based on the research question and the literature reviewed:

$\mathrm{H} \mathrm{1}$ : Organisations in the automotive industry cluster are highly ethical due to the presence of ethical leadership.

H 1A: Leadership in the automotive industry cluster display high levels of ethical commitment and conduct.

H 1B:Leadership in the automotive industry cluster have the required infrastructure and interventions in place to support an ethical environment.

H 1C: Leadership in the automotive industry cluster display high levels of compliance with external governance and legislative requirements.

Tables corresponding to each of the hypotheses are used to present and analyse the results of the study.

\subsection{Research methodology}

A quantitative approach was selected as it is objective, relatively simple to administer, offers a speedy method for data collection and allows for the data collected to be specific and measurable.

\subsection{Measuring instrument}

A structured, closed-ended, questionnaire was used to collect the data. The questionnaire which comprised of three sections: Section A- Biographical Information; Section B - Business Ethics and Section C - Organisational Values, was made up of a total of 147 items. A Likert-type rating scale with an unequal $1-5$ agreement format was selected for sections $B$ and $C$ of the questionnaire. The instrument was based on the questionnaire prepared by Mey (2004) when conducting a study involving companies in the automotive industry cluster in the Eastern Cape. In addition, it was revised and improved upon according to the literature that was reviewed.

An online questionnaire was selected to increase the response rate. The questionnaire was published on the Nelson Mandela Metropolitan University's (NMMU) web survey site which respondents could access electronically via a link provided in an e-mail that was sent to them. To encourage honesty, it was emphasised that the data collected would be treated confidentially and that the respondents would not be personally identifiable.

As the study involved human subjects, ethical clearance was obtained from the Research Ethics Committee (Human) (REC-H) of the NMMU prior to the commencement of the study. Additionally, respondents were requested in the cover letter to report any ethical concerns or issues to the chairperson or secretary of the REC-H.

\subsection{Data collection}

Primary data was collected by means of a questionnaire while secondary data sources comprised of books, journals, and electronic databases. A closed-ended questionnaire was used as this is less time consuming for the individual completing it. A pilot study was conducted among 17 companies operating in the Eastern Cape automotive industry, out of which ten individuals responsible for business ethics and organisational values within their companies responded to the 
questionnaire. Feedback from the pilot study was incorporated into the questionnaire before it was more widely disseminated.

\subsection{Sampling method}

The target population for the study comprised of 178 companies involved in the Eastern Cape automotive industry that were listed as members of the Automotive Industry Development Centre (AIDC) and or the Nelson Mandela Bay Business Chamber (NMBBC). However, due to closures, mergers and acquisitions, the population for the study was reduced to 100 companies, of which all were sampled. As such, the cover letter and the link to the questionnaire were mailed electronically to 100 companies, including those that had participated in the pilot study. The units of analysis for the study were individuals, one from each company, (Chief Executive Officers, Directors, Human Resource professionals and Line Managers) who are responsible for business ethics and organisational values in their companies.

Following the dissemination of the initial email, weekly follow-ups with the companies were done by telephone and email. The final response rate for the study was 46 per cent, which is regarded as acceptable for an email study and particularly one that utilised data collection from organisations (Baruch \& Holtom, 2008; Nulty, 2008). Furthermore, the researchers found no reason to doubt that the responses obtained were representative of the population.

\subsection{Data analysis}

Statistica Version 10 and SPSS Version 20 software packages were used to do the analysis of the data. The respondents' responses were numbered from 1 to 46 while the questions were labelled according to their appearance on the questionnaire.

\subsection{Validity and reliability of the research}

Validity was ensured by reviewing literature relating to the research as well as through the use of an appropriate questionnaire generated from aspects highlighted in the literature reviewed.

In order to ensure the reliability of the questions asked in the questionnaire, they were designed to be as simple as possible and understandable for the intended sample. In addition, all respondents were required to answer the same questions.

\section{Data Analysis and Interpretation of Results}

The selected rating scale used in this study is derived from a five-point Likert-type rating with differing discrete intervals, as is reflected below:

$$
\begin{array}{lll}
{[1.0-1.8)} & {[1.8-2.6)[2.6-3.4)(3.4-4.2](4.2-5.0)} \\
\text { Very Low } & \text { Low Medium High Very High }
\end{array}
$$

The mathematical parentheses used indicate "value included" in the case of a square bracket and "value excluded" in the case of a round bracket. By using this scale, a more accurate reflection and rating mechanism is generated, either to support or not to support the stated hypotheses of the study.

Table 1. Descriptive statistics

\begin{tabular}{|l|c|c|c|c|c|c|c|}
\hline Item & Valid N & Mean & Median & Minimum & Maximum & Std.Dev. & Skewness \\
\hline Principles of good governance (Q11) & 46 & 3.96 & 4.00 & 1.43 & 5.00 & 0.90 & -1.07 \\
\hline Social responsibility and social standards (Q14) & 46 & 3.83 & 4.00 & 1.00 & 5.00 & 1.02 & -0.83 \\
\hline Whistleblowing (Q15) & 46 & 3.90 & 4.20 & 1.40 & 5.00 & 1.04 & -1.07 \\
\hline Ethical organisational culture (Q16) & 46 & 4.03 & 4.14 & 1.57 & 5.00 & 0.77 & -0.96 \\
\hline Characteristics of an ethical organisational culture (Q18) & 46 & 4.22 & 4.31 & 2.75 & 5.00 & 0.58 & -0.30 \\
\hline Importance of organisational values relating to performance (Q20) & 46 & 4.68 & 5.00 & 3.17 & 5.00 & 0.48 & -1.49 \\
\hline Importance of organisational values relating to people (Q21) & 46 & 4.54 & 4.82 & 2.45 & 5.00 & 0.62 & -1.71 \\
\hline Values, leadership and communication (Q23) & 46 & 3.84 & 3.81 & 2.17 & 5.00 & 0.77 & -0.19 \\
\hline
\end{tabular}

For this analysis, a reference constant value of 3.4 was decided on, given the rating scale above. With this information 
and the mean values as reflected in Table 1 above, it is clear that all the calculated mean values of the items, as listed in Table 1, is significantly larger than the reference constant value and is in the high to very high ranges of the rating scale. In considering the column labelled "Skewness" it is also clear that the majority of respondents tended towards the higher values on the five-point Likert-scale used. The graphical representation of the values per measured construct follows:

\section{Graphical Representation per Measured Construct}

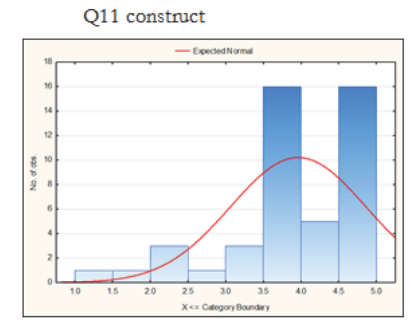

Q15 construct

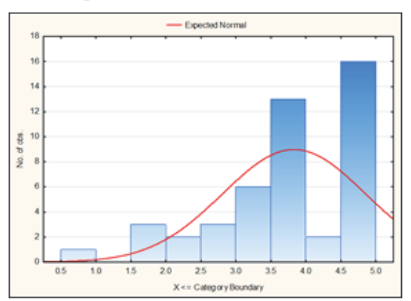

Q 18 construct

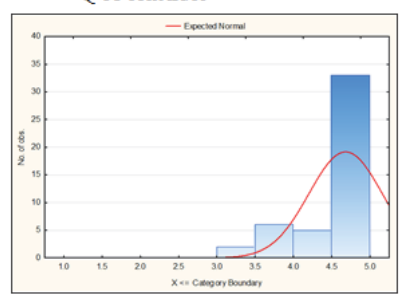

Q14 construct

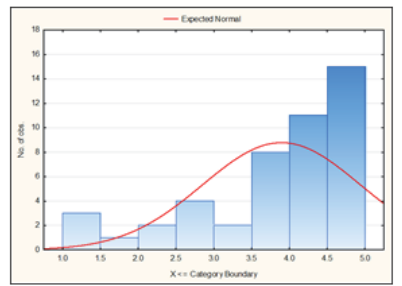

Q 16 construct

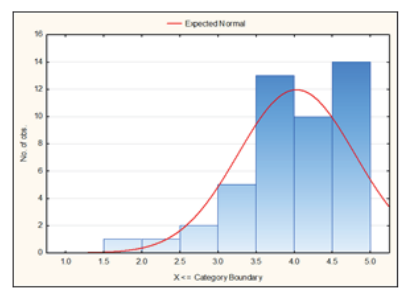

Q 20 construct

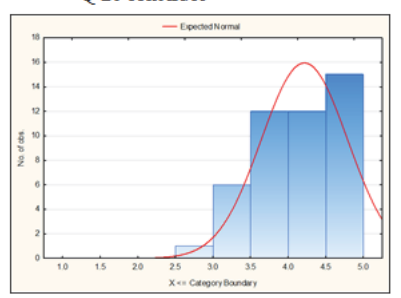

Due to the nature and sample size of the study, it was decided not to use a conventional factor analysis, but to rather concentrate on a reliability/item analysis, linked to Cronbach Alpha values. With this as the method of analysis, it was decided, given the guiding principles of the methodology used and the nature of the study that 0.35 would be used as the reference value for the reliability/item analysis and that a Cronbach Alpha value of 0.7 would be seen as acceptable. Any values above these values would then be seen as significant, indicating reliable internal consistency of the construct measured, and supportive of the stated hypothesis.

The tables below will expound the constructs measured and will indicate the relevant values attached to each construct, given the statistical analysis.

Table 2. Principles of good governance in the organisation

\begin{tabular}{|l|c|}
\hline Item & Item Total Correlation \\
\hline Discipline & 0.80 \\
\hline Transparency & 0.77 \\
\hline Independence & 0.81 \\
\hline Accountability & 0.79 \\
\hline Responsibility & 0.91 \\
\hline Fairness & 0.93 \\
\hline Social Responsibility & 0.79 \\
\hline
\end{tabular}

Cronbach Alpha: 0.95।

Source: Question 11 of questionnaire 
Table 3. Social Responsibility and social standards in the organisation

\begin{tabular}{|l|c|}
\hline Item & Item Total Correlation \\
\hline Social and Economic Development & 0.77 \\
\hline Good Corporate Citizenship & 0.89 \\
\hline Impact of Company's activities, products, services & 0.80 \\
\hline Consumer relations & 0.90 \\
\hline Labour and employment & 0.72 \\
\hline
\end{tabular}

Cronbach Alpha: 0.93

Source: Question 14 of questionnaire

Table 4. Whistleblowing

\begin{tabular}{|l|c|}
\hline \multicolumn{1}{|c|}{ Item } & Item Total Correlation \\
\hline Organisation encourages and recognises disclosure & 0.69 \\
\hline Organisation has strategies in place to deal with internal reporting of unlawful/irregular practices & 0.80 \\
\hline Employees are made aware of whistleblower protection & 0.81 \\
\hline Organisation supports/protects whistleblowers & 0.81 \\
\hline Organisation offers incentives to report on unlawful/irregular practice & 0.25 \\
\hline Organisation would be willing to make changes based on complaints received & 0.59 \\
\hline
\end{tabular}

Cronbach Alpha: 0.83

Source: Question 15 of questionnaire

Table 5. Interventions to establish an ethical organisational culture

\begin{tabular}{|l|c|}
\hline Item & Item Total Correlation \\
\hline Code of ethics & 0.45 \\
\hline Ethics Training & 0.82 \\
\hline Ethics-focussed reward system & 0.47 \\
\hline Top management commitment & 0.33 \\
\hline Ethics audit/assessment & 0.76 \\
\hline Whistleblower protection & 0.62 \\
\hline Ethics committee & 0.77 \\
\hline Ethics hotline/helpline & 0.88 \\
\hline
\end{tabular}

Cronbach Alpha: 0.87

Source: Question 16 of questionnaire

Table 6. Characteristics of an ethical organisational culture

\begin{tabular}{|l|c|}
\hline Item & Item Total Correlation \\
\hline Competent leadership & 0.51 \\
\hline Ethics training & 0.62 \\
\hline Code of ethics & 0.70 \\
\hline Ethics officer & 0.70 \\
\hline Whistleblower protection & 0.53 \\
\hline Ethics-focussed reward system & 0.46 \\
\hline Ethical conduct when dealing with stakeholders & 0.73 \\
\hline Good corporate governance & 0.41 \\
\hline
\end{tabular}

Cronbach Alpha: 0.83

Source: Question 18 of questionnaire

Table 7. Standards to govern individual behaviour in the organisation

\begin{tabular}{|l|c|}
\hline Item & Item Total Correlation \\
\hline Is the organisation's Statement of Values in its mission? & 0.51 \\
\hline Is the organisation's Statement of Values prepared by senior management? & 0.44 \\
\hline Is the organisation's Statement of Values inclusive of non-managerial staff? & 0.27 \\
\hline
\end{tabular}

Cronbach Alpha: 0.55

Source: Question 19 of questionnaire 
Table 8. Organisational values as it relates to organisation performance

\begin{tabular}{|l|c|}
\hline Item & Item Total Correlation \\
\hline Achieve financial results & 0.77 \\
\hline Building long-term shareholder value & 0.78 \\
\hline Product/service quality & 0.83 \\
\hline Strong brand reputation & 0.66 \\
\hline Industry leadership & 0.85 \\
\hline Commitment to organisational goals & 0.81 \\
\hline
\end{tabular}

Cronbach Alpha: 0.92

Source: Question 20 of questionnaire

Table 9. Organisational values as it relates to staff

\begin{tabular}{|l|c|}
\hline Item & Item Total Correlation \\
\hline Staff training and development & 0.80 \\
\hline Employee assistance programmes & 0.67 \\
\hline Teamwork & 0.82 \\
\hline Fairness/equality & 0.90 \\
\hline Respect for others & 0.86 \\
\hline Open communication & 0.84 \\
\hline Appreciation for diversity & 0.88 \\
\hline Excellence & 0.84 \\
\hline Honesty and integrity & 0.73 \\
\hline Motivation & 0.91 \\
\hline Recognition and rewards & 0.81 \\
\hline
\end{tabular}

Cronbach Alpha: 0.96

Source: Question 21 of questionnaire

Table 10. Values, leadership and communication

\begin{tabular}{|l|c|}
\hline Item & Item Total Correlation \\
\hline Relevance of organisational core values to business activities & 0.61 \\
\hline Relevance of organisational core values to staff & 0.53 \\
\hline Staff training on organisational values & 0.66 \\
\hline Senior management practises core values & 0.73 \\
\hline Senior management coach employees on core values & 0.73 \\
\hline Statement of Values correctly reflects the current core values & 0.80 \\
\hline Core values is congruent with senior management decisions & 0.79 \\
\hline Core values is congruent with line management decisions & 0.63 \\
\hline Internal and external communication reflect core values & 0.76 \\
\hline Congruency between individual values and organisational values are checked & 0.67 \\
\hline Recognition is granted to employees who achieve in line with core values & 0.78 \\
\hline Penalties are instituted against transgressors of core values & 0.74 \\
\hline Core values are communicated on a regular basis & 0.81 \\
\hline Core values are effectively communicated & 0.87 \\
\hline Core values are communicated verbally & 0.71 \\
\hline Core values are communicated in writing & 0.61 \\
\hline Core values are debated and revised annually & 0.74 \\
\hline Core values are updated annually & 0.73 \\
\hline
\end{tabular}

Cronbach Alpha: 0.95

Source: Question 23 of questionnaire

As can be seen from the analysis above, all of the Cronbach Alpha values are significantly above the benchmark value of 0.7. In the case of the individual item total correlation values, there are only three values less than the benchmark value of 0.35 . These items are reflected in Tables 4, 5, 7 and are shaded in grey. This is indicative of the fact that these three 
values do not correlate, optimally, with the other items in that particular construct.

In terms of analysing and interpreting the results in greater detail, further sets of analyses were conducted. The results are reflected in tables below.

In correlating the extent to which business practices account for community impact (Q10) with principles of good governance (Q11) and organisational social responsibility and social standard (Q14), it was found that there is a strong positive relationship between these constructs with $p$-values less than 0.05 and the Spearman correlations values higher than 0.5. These results are reflected in Table 11 below.

Table 11. Community impact in relation to good governance and social responsibility

\begin{tabular}{|c|c|c|}
\cline { 2 - 3 } \multicolumn{1}{c|}{} & Q11 construct & Q14 construct \\
\hline Q10.1 & 0.773 & 0.561 \\
\hline
\end{tabular}

Table 12 below indicates the correlation between community impact of business practices (Q10) and issues relating to ethical corporate governance (Q12). A statistically significant relationship was detected with the nature and extent of social transformation (Q12.1). The results from Table 12 reflect this, where it is clear that with a p-value of 0.00035 there exists a statistically significant relationship. The effect size measure, as given by Cramer's $V(0.47)$ also indicates a medium strength relationship in terms of practical significance. The other relations (Q12.2 - Q12.5) proved not to be statistically significant with $p$-values in excess of 0.05 and will, therefore, not be reported.

Table 12. Community impact in relation to social transformation

2-Way Summary Table: Observed Frequencies

\begin{tabular}{|c|c|c|c|c|}
\hline Q10 1new & Q12.1Y & Q12.1 N & Q12.1 DK & Row Totals \\
\hline Disagree & 1 & 8 & 5 & 14 \\
\hline Row $\%$ & $7.14 \%$ & $57.14 \%$ & $35.71 \%$ & \\
\hline Neutral & 11 & 6 & 2 & 19 \\
\hline Row \% & $57.89 \%$ & $31.58 \%$ & $10.53 \%$ & \\
\hline Agree & 12 & 1 & 0 & 13 \\
\hline Row \% & $92.31 \%$ & $7.69 \%$ & $0.00 \%$ & \\
\hline Totals & 24 & 15 & 7 & 46 \\
\hline
\end{tabular}

$p=0.00035$, Cramer's $V=0.47$

From Table 12 it is also clear that respondents who agreed with the statement in Q10 also consistently answered "yes" to Q12(1) (92,31\%), while respondents who disagreed with Q10 also consistently said "no" to Q12(1) $(57,41 \%)$.

To, further, explore the value of business ethics to a diverse grouping of stakeholders and to establish the commitment of the chief executive office, senior management and direct line management, the following correlation analyses were done: Management commitment (Q4) to Customers (Q6). See Table 13; Management commitment (Q4) to Shareholders (Q7). See Table 14; Management commitment (Q4) to Suppliers (Q8) See Table 15 and Management commitment (Q4) to Society (Q9). See Table 16.

Table 13. Management commitment to customers

\begin{tabular}{|c|c|c|c|c|}
\cline { 2 - 5 } \multicolumn{1}{c|}{} & Q6.1 & Q6.2 & Q6.3 & Q6.4 \\
\hline Q4.1 & 0.386 & 0.312 & 0.329 & 0.330 \\
\hline Q4.2 & 0.545 & 0.405 & 0.444 & 0.530 \\
\hline Q4.3 & 0.467 & 0.353 & 0.507 & 0.422 \\
\hline
\end{tabular}

All correlations are statistically significant, with p-values smaller than 0.05 .

Table 14. Management commitment to shareholders

\begin{tabular}{|c|c|c|}
\cline { 2 - 3 } \multicolumn{1}{c|}{} & Q7.1 & Q7.2 \\
\hline Q4.1 & $0.216^{*}$ & 0.323 \\
\hline Q4.2 & 0.362 & 0.481 \\
\hline Q4.3 & $0.287^{*}$ & 0.555 \\
\hline
\end{tabular}

All correlations are statistically significant, with $p$-values smaller than 0.05 , except those with an asterisk $\left(^{\star}\right)$. 
Table 15. Management commitment to suppliers

\begin{tabular}{|c|c|c|c|}
\cline { 2 - 4 } \multicolumn{1}{c|}{} & Q8.1 & Q8.2 & Q8.3 \\
\hline Q4.1 & $0.184^{*}$ & 0.354 & 0.536 \\
\hline Q4.2 & 0.494 & 0.523 & 0.437 \\
\hline Q4.3 & 0.552 & 0.459 & 0.299 \\
\hline
\end{tabular}

All correlations are statistically significant, with p-values smaller than 0.05 , except those marked with an asterisk (*).

Table 16. Management commitment to society

\begin{tabular}{|c|c|c|c|}
\cline { 2 - 4 } \multicolumn{1}{c|}{} & Q9.1 & Q9.2 & Q9.3 \\
\hline Q4.1 & 0.382 & 0.392 & 0.324 \\
\hline Q4.2 & 0.463 & 0.483 & 0.393 \\
\hline Q4.3 & 0.422 & 0.456 & 0.373 \\
\hline
\end{tabular}

All correlations are statistically significant with $\mathrm{p}$-values smaller than 0.05 .

With these statistical analyses, it can now be affirmed that the stated hypotheses (see section 3.2) can be supported. It can, therefore, be concluded that organisations in the automotive industry cluster are highly ethical due to the presence of ethical leadership.

\section{Recommendations, Limitations and Conclusion}

The following recommendations emanate from the results of the study and the literature reviewed:

An ethical organisation requires its leadership and management to be highly committed to ethical business objectives, practices and conduct and to have clear policies and guidelines regarding acceptable ethical behaviour for all stakeholders (employees, customers, suppliers and shareholders). In addition, the presence of ethics related standards and infrastructure, most notably a Code of Ethics, is critical to ensuring an ethical environment. Furthermore, leadership's compliance with the principles of good governance and legislative requirements such as the Social and Ethics Committee and whistleblower protection is imperative for an ethical organisation.

A possible limitation of the study is that the sample size of 46 , while being adequate for statistical analysis, may restrict the ability to generalise the findings beyond the related hypotheses. Also, all 46 respondents were drawn from the automotive industry in the Eastern Cape. Further research with a larger sample size, across different sectors and geographical areas, would add value and improve the generalisability of this research.

High profile scandals have brought about a renewed interest in business ethics and, in particular, the need for a better understanding of the roles and responsibilities of leadership in promoting ethical behaviour. Against this background a study, which measured and analysed the ethical practices of the leadership in organisations operating in the Eastern Cape automotive industry, was conducted. The results, of which, revealed that the organisations in the sample are in fact highly ethical due to ethical leaders who ensure the presence of ethics related interventions, such as a Code of Ethics, clear policies and codes for stakeholders, and encouragement of the disclosure of unethical behaviour, all of which are essential for establishing and maintaining an ethical organisational environment.

\section{References}

Archer, D. (2008). Ensuring an ethical organisation. CMA Management, November 2008, 32-36.

Barnard, L.D. (2012). "Assessing some aspects of managerial ethics within the South African business environment". Masters in Business Administration mini dissertation. North-West University.

Baruch, Y., \& Holtom, B.C. (2008). Survey response rate levels and trends in organizational research. Human Relations, 61(8), 11391160.[Online] Available: http://www18.georgetown.edu/data/people/bch6/publication-39527.pdf (March 10, 2014)

Bello, S.M., (2012). Impact of ethical leadership on employee job performance. International Journal of Business and Social Science, 3(11), 228-236.

Brown, M.E., Trevino, L.K., \& Harrison, D.A. (2005). Ethical leadership: a social learning perspective for construct development and testing. Organizational Behaviour and Human Decision Processes, 97, 117-134.

BusinessDictionary.com. [Online] Available: http://www.businessdictionary.com/definition/corporate-governance.html (September 10, 2012)

Caldwell, C., Hayes, L.A., \& Long, D.T. (2010). Leadership, trustworthiness and ethical stewardship. Journal of Business Ethics, 96, 497-512.

Chauhan, D., \& Chauhan, S.P.(2002). Ethical dilemmas faced by managers: some real life cases. Indian Journal of Industrial Relations, $37(3), 370-385$.

Companies Act 71 of 2008 [Online] Available: http://www.justice.gov.za/legislation/acts/2008-071amended.pdf (March 10, 2014)

Ethics Resource Centre. (2012). National business ethics survey of fortune 500 employees. [Online] Available: http://www.ethics.org Inbes/ (October 10, 2012) 
Ethics Resource Centre, (2013). National business ethics survey of the U.S. workforce. [Online] Available: http://www.ethics.org/ downloads/2013NBESFinalWeb.pdf (March 10, 2014)

Fieser, J. (n.d). Business ethics. [Online] Available: http://rio.mhs.narotama.ac.id/2012/01/02/tugas-personal-business-ethics-by-jamesfieser/ (October 10, 2012)

Fombrun, C., \& Foss, C. (2004). Business ethics: corporate responses to scandal. Corporate Reputation Review, 7(3), $284-288$.

Freeman, R.E., \& Reed, D.L. (1983). Stockholders and stakeholders: a new perspective on corporate governance. California Management Review, 25(3), 88-106.

Freeman, R.E. (2001). Stakeholder theory of the modern corporation. [Online] Available: http://academic.udayton.edu/lawrenceulrich IStakeholder\%20Theory.pdf (March 10, 2014)

Granger, D. (2011). 5 steps to building an ethical culture. [Online] Available: http://blog.rogerscorp.com/2011/08/02/5-steps-to-buildingan-ethical-culture/ (March 5, 2013)

Grojean, M.W., Resick, C.J., Dickson, M.W., \& Smith, D.B (2004). Leaders, values and organizational climate: examining leadership strategies for establishing an organizational climate regarding ethics. Journal of Business Ethics, 55, 223-241.

Gruble, C. (2011). Defining business ethics. Business Ethics Review [Online] Available: http://businessethicsreview.wordpress.com /2011/06/21/defining-business-ethics/ (March 5, 2013)

Hansen, S.D. (2011). Ethical leadership: a multifoci social exchange perspective. The Journal of Business Inquiry, 10(1), 41-55.

IBM, 2011. SPSS Version 20. [online] Available at: < http://www-01.ibm.com/software/analytics/spss/products/statistics/upgrade.html (October 10, 2012). Institute of Directors Southern Africa. (2009). King code of governance for South Africa 2009. [Online]. Available: http://www.ecgi.org/codes/documents/king3.pdf (October 10, 2012)

Jondle, D., Ardichvilli, A., \& Mitchell, J. (2014). Modeling ethical business culture: development of the ethical business culture survey and its use to validate the CEBC model of ethical business culture. Journal of Business Ethics, 119, 29-43.

Josephson, M. (2012). Business ethics insight: The three levels of ethical issues in business. [Online] Available: http://josephsoninstitute .org/business/blog/2012/07/business-ethics-insight-the-three-levels-of-ethical-issues-in-business/ (March 5, 2013)

Joyner, B.E., \& PAYNE, D. (2002). Evolution and implementation: a study of values, business ethics and corporate social responsibility. Journal of Business Ethics, 41, 297-311.

Kaptein, M. (2011). Towards effective codes: testing the relationship with unethical behaviour. Journal of Business Ethics, 99, $233-251$.

Khar, B,, Praveen, M., \& Aggarwal, M. (2011). A quasi experimental study on leadership effectiveness and ethics. Review of Management, 1(2), 107-115.

Knights, D., \& O'Leary, M. (2005). Reflecting on corporate scandals: the failure of ethical leadership. Business Ethics: A European Review, 14(4), 359-366.

Lloyd, H., \& Mey, M.R. (2010). An ethics model to develop an ethical organisation. South African Journal of Human Resources Management, 8(1),1-12 [Online] Available: http://www.sajhrm.co.za/index.php/sajhrm/article/view/218/252 (October 10, 2012)

Mayer, D.M. (2011). How can we create ethical organizations? [Online] Available: http://www.centreforpos.org/2011/07/how-can-wecreate-ethical-organizations/ [October 9, 2012)

Mey, M.R. (2004). "The development of a human resource model that supports the establishment of an ethical organisational culture." Doctor Technologiae thesis, Port Elizabeth Technikon.

Miethe, T.D., \& Rothschild, J. (1994). Whistleblowing and the control of organizational misconduct.

Sociological Inquiry, 64(3), 322-347. [Online] Available:http://onlinelibrary.wiley.com/doi/10.1111/j.1475-682X.1994.tb00395.x/abstract (March 10, 2014)

Minkes, A.L., Small, M.W., \& Chatterjee, S.R. (1999). Leadership and business ethics: does it matter? Implications for Management. Journal of Business Ethics, 20, 327-335.

Nulty, D.D. (2008). The adequacy of response rates to online and paper surveys: what can be done? Assessment \& Evaluation in Higher Education, 33(3), 301-314. [Online] Available: http://www.uaf.edu/files/uafgov/fsadmin-nulty5-19-10.pdf (March 12, 2014)

Pattan, J.E. (1984). The business of ethics and the ethics of business. Journal of Business Ethics [e-journal], 3,1-19. Available through: EBSCOhost database academic search premier (September 10, 2012)

Protected Disclosures Act 26 of 2000, [Online] Available: http://www.justice.gov.za/legislation/acts/2000-026.pdf (March 11, 2013)

Robbins, S.P., \& JUDGE, T.A. (2009). Organizational behaviour (13 th ed). Upper Saddle River, NJ: Pearson Education, Inc.

Rossouw, D., \& Van Vuuren, L. (2010). Business Ethics (4th ed.). Southern Africa: Oxford University Press.

Rossouw, D. \& Van Vuuren, L. (2013). Business Ethics ( $5^{\text {th }}$ ed.). Southern Africa: Oxford University Press.

Schoeman, C. (2012). How ethical is South Africa? Ethical Living [Online] Available: http://www.ethicsmonitor.co.za/Articles/064-065.pdf (October 10, 2012)

Singh, K.(2011). Developing ethics at the workplace through transformational leadership: a study of business organizations in India. Journal of Knowledge Globalization, 4(2).

StatSoft. (2013). Statistica Version 11. [Online] Available: http://www.statsoft.com/support/download/installation-instructions (October 10, 2012).

Van Vuuren, L.J. (2002). Institutionalising business ethics: a multi-level strategy. Management Dynamics, 11(2): 21-27. [Online] Available: http://reference.sabinet.co.za/document/EJC69643 (March 11, 2014)

Van Zyl, E., \& Lazenby, K. (1999). Ethical behaviour in the South African organisational context: essential and workable. Journal of Business Ethics, 21, 15-22.

Verschoor, C.C. (1998). A study of the link between a corporation's financial performance and its commitment to ethics. Journal of Business Ethics, 17, 1509-1516. 